\title{
Temperature Thresholds and Degree-Day Model for Marmara gulosa (Lepidoptera: Gracillariidae)
}

\author{
M. J. O’NEAL ${ }^{1}$ D. H. HEADRICK, ${ }^{1,2}$ GREGORY H. MONTEZ, ${ }^{3}$ and E. E. GRAFTON-CARDWELL ${ }^{3}$
}

J. Econ. Entomol. 104(4): 1286-1293 (2011); DOI: 10.1603/EC10438

\begin{abstract}
The developmental thresholds for Marmara gulosa Guillén \& Davis (Lepidoptera: Gracillariidae) were investigated in the laboratory by using $17,21,25,29$, and $33^{\circ} \mathrm{C}$. The lowest mortality occurred in cohorts exposed to 25 and $29^{\circ} \mathrm{C}$. Other temperatures caused $>10 \%$ mortality primarily in egg and first and second instar sap-feeding larvae. Linear regression analysis approximated the lower developmental threshold at $12.2^{\circ} \mathrm{C}$. High mortality and slow developmental rate at $33^{\circ} \mathrm{C}$ indicate the upper developmental threshold is near this temperature. The degree-day (DD) model indicated that a generation requires an accumulation of 322 DD for development from egg to adult emergence. Average daily temperatures in the San Joaquin Valley could produce up to seven generations of $M$. gulosa per year. Field studies documented two, five, and three overlapping generations of M. gulosa in walnuts (Juglans regia L.; Juglandaceae), pummelos (Citrus maxima (Burm.) Merr.; Rutaceae), and oranges (Citrus sinensis (L.) Osbeck; Rutaceae), for a total of seven observed peelminer generations. Degree-day units between generations averaged 375 DD for larvae infesting walnut twigs; however, availability of green wood probably affected timing of infestations. Degree-day units between larval generations averaged 322 for pummelos and 309 for oranges, confirming the laboratory estimation. First infestation of citrus occurred in June in pummelo fruit and August in orange fruit when fruit neared $60 \mathrm{~mm}$ in diameter. Fruit size and degree-day units could be used as management tools to more precisely time insecticide treatments to target the egg stage and prevent rind damage to citrus. Degree-day units also could be used to more precisely time natural enemy releases to target larval instars that are preferred for oviposition.
\end{abstract}

KEY WORDS lower developmental threshold, degree-day, citrus peelminer

Marmara gulosa Guillén \& Davis (Lepidoptera: Gracillariidae) larvae feed as subsurface miners in fruit and stems of plants such as bean, cotton (Gossypium hirsutum L.), cucurbits (Cucurbita spp.), grape (Vitis spp.), nut, oleander (Nerium oleander L.), willow (Salix spp.) and various other crops, and it is periodically an economic pest of citrus (Citrus spp.) fruit in the southwestern United States (Atkins 1961, 1971; Reeves 1995; Gibson et al. 1997; Guillén et al. 2001, 2003; Godfrey et al. 2003; Grafton-Cardwell et al. 2003). Larvae create serpentine mines in the rind of citrus fruit, rendering it unacceptable for fresh market sale (Atkins 1961, Reeves 1995). In the San Joaquin Valley of California, certain varieties of citrus such as grapefruit (Citrus paradisi Macfad.; Rutaceae), pummelo (Citrus maxima Merr.; Rutaceae), and 'Fukumoto', 'Atwood', 'Thompson Improved' and 'Barnfield' navels [Citrus sinensis (L.) Osbeck; Rutaceae] are especially susceptible to mining by M. gulosa. Mining damage is difficult to control with insecticide sprays because the moths prefer to oviposit on fruit hanging low and

\footnotetext{
${ }^{1}$ Department of Horticulture and Crop Science, California Polytechnic State University, San Luis Obispo, CA 93407.

${ }^{2}$ Corresponding author, e-mail: dheadric@calpoly.edu.

${ }^{3}$ Department of Entomology, University of California, Riverside, CA 92521 .
}

inside the tree during periods when the fruit is rapidly outgrowing the treatment. In addition, treatments must be applied before the initiation of egg hatch to prevent mining damage and determining moth flights that precede oviposition is difficult due to the weak attractiveness of the synthetic pheromone (McElfresh et al. 2009).

An investigation by Guillén and Heraty (2004) of the growth and developmental of M. gulosa indicated that larvae complete four to seven feeding instars depending on environment conditions. Guillén and Heraty (2004) also determined that temperature influenced mortality of M. gulosa; however, the developmental thresholds and degree-days (DD) required to complete a generation were not investigated. A model of the effect of temperature on growth and development of M. gulosa stages could aid management of this pest because control tactics vary by life stage; for example, predicting moth flights would improve timing for treatments that affect the egg stage. In addition, native gracillariid parasitoids preferentially use fourth and fifth instar larvae as hosts (Guillén et al. 2007), and the success of establishing biological control agents could be improved through precise timing of field releases. The objectives of these laboratory studies were to determine the relationship be- 
tween temperature and the developmental rate of $M$. gulosa and to use these data to develop a degree-day model that could be verified in the field and used to better manage the pest.

\section{Materials and Methods}

The laboratory colony of $M$. gulosa was initiated with specimens collected from field-infested zucchini squash, Cucurbita pepo (L.), 'Ambassador' (Cucurbitaceae) (Seminis, Oxnard, CA) in 2004 and maintained on Ambassador squash at the Kearney Agricultural Center, Parlier, CA.

M. gulosa moths were reared in Bug Dorm 2 (Bioquip, Rancho Dominguez, CA) collapsible $300-\mathrm{cm}^{3}$ plastic cages with cloth openings for ventilation held at $26 \pm 2^{\circ} \mathrm{C}, 40 \pm 5 \% \mathrm{RH}$, and a photoperiod of 12:12 (L:D) h. Each cage contained $\approx 500$ moths that were provided a $10 \%$ sucrose solution in a vial with a cotton wick and honey applied to wax paper strips. Squash were exposed to the moths for $24-48 \mathrm{~h}$, and then the squash were held in trays on moist vermiculite until leafminer larvae began to pupate. Squash were then moved to paper towels that provided an irregular surface necessary for pupation. Pupae were finally placed into the plastic cages for moth emergence.

For the study, 168 uninfested Ambassador zucchini squash were obtained from a field planting at the Kearney Agricultural Center during 2005. Squash were gently rinsed with deionized water and allowed to air dry. Twenty-four squash were placed in each of seven growth cabinets (Percival Scientific, Perry, IA) and left exposed to 500 mated moths for $12 \mathrm{~h}$. Cabinets were held at $26 \pm 2{ }^{\circ} \mathrm{C}$ with $30-40 \% \mathrm{RH}$ and a photoperiod of 12:12 (L:D) h using Sylvania Gro-lux 40Watt florescent lights.

Squash were placed in 43.8 - by 29.5 - by $16.5-\mathrm{cm}$ plastic trays covered with $5 \mathrm{~cm}$ of moistened coarse vermiculite (Orchard Supply Hardware, Fresno, CA). Oviposition was verified by observation of eggs on squash using a stereo dissecting microscope. Each squash was numbered with a permanent marker; four squash were placed in each of six trays per temperature cabinet. Temperature cabinets were held at 17 , $21,25,29$, and $33 \pm 0.5^{\circ} \mathrm{C}$. Squash remained on the vermiculite and were misted daily with distilled water until egg hatch. After egg hatch, squash were transferred to 43.8 - by 29.5 - by 16.5 -cm plastic trays covered with paper towels. Infested squash were maintained under fluorescent light on a photoperiod of 14:10 (L:D) h. Each growth chamber contained a 2,000-ml beaker of saturated table salt solution at a rate of 368.5 $\mathrm{g}$ salt/ liter water to maintain relative humidity at $90 \pm$ 5\% (Winston and Bates 1960). Temperature and relative humidity were verified by a digital temperature and humidity monitor (Thermo Fisher Scientific, Waltham, MA) in each temperature cabinet.

Development of M. gulosa cohorts were tracked by labeling individuals on each squash with a pen, for a total of 120 larvae per treatment; observations were recorded daily. Larval head capsule width to $0.1 \mathrm{~mm}$ was evaluated on each sap-feeding larva by using an ocular micrometer fitted in the eyepiece of a dissecting microscope. Completion of sap-feeding larval instars was determined by a period of larval quiescence before molting followed by an increase in head capsule width of $\approx 0.1 \mathrm{~mm}$, in addition to the presence of a cast exuvium. Identification of the nonfeeding spinning larval instar was through changes in morphology and color of the larva (Guillén et al. 2001). The time period that larvae-infested squash were brought outside of temperature cabinets for measurement and assessment of survival was limited to an average of 1.5 min to minimize the effect of temperature fluctuations on larval development. Dates of egg hatch, sap-feeding and spinning larval instars, pupation, adult moth emergence, and mortality of each individual were recorded. Mature larvae emerged from the squash and pupated in the crevices of the paper toweling. Pupae were separated by cutting the paper towel and placing the pupae individually in 20-dram glass vials plugged with cotton and returned to the temperature cabinet. Adult gender was determined by microscopic examination of the genitalia (Guillén et al. 2001). The mean percentage of males was calculated and the proportions compared for the five temperature regimes using analysis of variance (ANOVA) and Fishers least significant difference (LSD) test $(P=0.05)$ (Statgraphics Centurion software, Statpoint Technologies, Warrenton, VA).

The mean percentage mortality $( \pm \mathrm{SEM})$ of each $M$. gulosa cohort for each temperature regime $(17,22,25$, 29 , and $33^{\circ} \mathrm{C}$ ) was calculated daily. Mean number of days for $50 \%$ of the population to complete each growth stage from oviposition through adult for each temperature was calculated, $\log (x+1)$ transformed and compared using ANOVA and Fisher's LSD test $(P=0.05)$.

The developmental times of individuals in the 17,21, 23 , and $29^{\circ} \mathrm{C}$ regimes were used to calculate a linear regression equation, $r^{2}$ value, lower developmental threshold, and degree-day accumulation for periods from oviposition to each growth stage through adult. Data for individuals exposed to $33^{\circ} \mathrm{C}$ were excluded from the analysis because of the high rate of mortality and slower developmental time for these individuals compared with $29^{\circ} \mathrm{C}$, indicating that these data were not in the linear portion of the response. The stage duration intervals were calculated using the reciprocal of the number of days to complete a stage $(1 / d)$ multiplied by 100 to give a value $>1$ (Amarasekare et al. 2008). The linear regression equation of temperature $(\mathrm{x})$ versus/stage duration in days $(\mathrm{y})$ was derived and the lower developmental thresholds for each stage were approximated by extrapolation of the regression to the $\mathrm{x}$-axis.

The degree-day accumulation for each stage was calculated as $1 /$ slope for the 50th percentile to complete the stage. The degree-day accumulation for oviposition through pupation was used to estimate a generation time for M. gulosa. Mean daily maximum and minimum temperatures were calculated for temperature data obtained from the Lindcove CIMIS station (http://www.cimis.water.ca.gov/cimis/) for 1976- 
2006. Degree-days were calculated using the method of Gilmore and Rogers (1958): degree-days $=[$ (daily maximum temperature ${ }^{\circ} \mathrm{C}-$ daily minimum temperature $\left.{ }^{\circ} \mathrm{C}\right) / 2$ ] - lower developmental threshold (LDT). The number of generations of M. gulos a for the San Joaquin Valley region was estimated by taking the cumulative number of degree-day units for 1 January through 31 December and dividing by the degree-day accumulation for $M$. gulosa needed to complete one generation.

During 2006, pheromone trapping and examination of twigs and fruit for M. gulosa larvae were conducted in nine sites: three walnut, Juglans regia L. (Juglandaceae), sites; three pummelo sites; and three navel orange, sites. Walnut site 1 (Farmersville, CA) was 28.33 ha planted in 1990, walnut site 2 (Exeter, CA) was 2.83 ha planted in 1998, and walnut site 3 (Woodlake, CA) was 20.23 ha planted in 1975. Site 4 (Ivanhoe, CA) was 'Chandler' pummelo, with the west half consisting of 1.21 ha planted in 1990 and the east half consisting of 1.21 ha planted in 1995. Site 5 (Visalia, CA) was Chandler pummelo, with the north half consisting of 8.9 ha planted in 1995 and the south half consisting of 8.1 ha planted in 1993. Site 6 (Exeter, CA) was 1.62 ha of Chandler pummelo in the south half planted in 1988 and the north half consisted of 1.21 ha 'Melogold' pummelo planted in 1988 and regrafted to Chandler scion in 2000. Site 7 (Farmersville, CA) consisted of 7.69 ha of 'Fukumoto' planted in 1998. Site 8 (Lindsay, CA) used Fukumoto scion on trifoliate rootstock, with the north half consisting of 2.02 ha planted in 1994 and the south half consisting of 2.02 ha planted in 1995. Site 9 (Strathmore, CA) consisted of 2.02 ha of 'Lane Late' interplanted with 'Powell' planted in 1995.

Sites were divided into four quadrants along cardinal axes. A delta pheromone trap (Trécé, Adair, OK) was placed at a height of $1.5 \mathrm{~m}$ in the center of each quadrant on 26 March 2006, for a total of four traps per site and 12 traps per host plant type. Each trap contained a rubber septum impregnated with the artificial sex pheromone for M. gulosa obtained from J. G. Millar (University of California, Riverside, CA) (McElfresh et al. 2009). Traps were checked weekly through 14 September for walnuts and through 2 November for citrus. The total number of male moths in each trap was counted in the field. Pheromone septa and traps were changed once every 4 wk. Moths per trap were averaged for each host plant type.

Measurement of the length (centimeters) of new green growth at the distal end of walnut twigs, and larval sampling was conducted on 100 randomly chosen twigs per quadrant in each walnut site weekly from 20 April through 3 August, after which twigs became unsuitable as a resource for $M$. gulosa larvae. The numbers of live, dead and emerged larvae were recorded. Larval instar was determined using a $15 \times$ hand lens (Bioquip, Rancho Dominguez, CA) and was based on the number of changes in mine width (Finch 2003). Data for twig length was averaged and data for first, late stage (third-fifth instar larvae), and emerged larval stages were combined for the three walnut sites.
One hundred fruit per quadrant in each pummelo and navel orange site were sampled for M. gulosa larvae 15 June through 2 November 2006. The number of live, dead, and emerged larvae and the instars of live larvae were recorded using the same methods as the walnut samples. The diameter (millimeters) of 10 randomly selected fruit per quadrant in each site was measured once weekly 15 June through 7 September for pummelos and 2 November for oranges using a fruit caliper (Fruit Growers Supply, Woodlake, CA). The fruit size was averaged for the three pummelo and for the three navel orange sites. The total number of first, late stage (third-fifth instar), and emerged larvae were totaled for the three pummelo and three orange sites and plotted by sample date.

Degree-day intervals between generations were calculated using a lower developmental threshold of $12.2^{\circ} \mathrm{C}$ and the degree-days calculated as described above for temperature data obtained from the Lindcove CIMIS station (http://www.cimis.water.ca.gov/ cimis / ) for 2006.

\section{Results}

Egg hatch of M. gulosa occurred at all temperatures tested, ranging from 111 to 120 individuals per treatment (Table 1). The incubation time before egg hatch, ranging from 3.0 to $10.7 \mathrm{~d}$, was significantly affected by temperature $(F=3,117$; $\mathrm{df}=4,576 ; P<0.0001)$. Incubation time decreased from 17 to $29^{\circ} \mathrm{C}$ and then increased again slightly at $33^{\circ} \mathrm{C}$. Eggs required 2.7 times longer for hatching when exposed to $17^{\circ} \mathrm{C}$ compared with $29^{\circ} \mathrm{C}$.

Development of $M$. gulosa larvae through five sapfeeding instars was observed with differences in larval head capsule widths of $0.1,0.2,0.3,0.4$, and $0.5 \mathrm{~mm}$. Development from oviposition through each sapfeeding larval instar was significantly affected by temperature for the first instar $(F=3,546 ; \mathrm{df}=4,527 ; P<$ $0.0001)$, second instar $(F=1,832 ; \mathrm{df}=4,480 ; P<$ $0.0001)$, third instar $(F=1,558$; df 4,$425 ; P<0.0001)$, fourth instar $(F=1,316 ; \mathrm{df}=4,397 ; P<0.0001)$, and fifth instar $(F=1,011$; df $=4,376 ; P<0.0001)$ stages (Table 1). Similar to the egg stage, $M$. gulosa larvae exhibited decreasing developmental time from 17 to $29^{\circ} \mathrm{C}$, and then developmental time increased for the cohort exposed to $33^{\circ} \mathrm{C}$. Larval instars 1-5 required 3.5-4.5 times longer to complete development at $17^{\circ} \mathrm{C}$ compared with $29^{\circ} \mathrm{C}$. Development from egg through the spinning larval instar also was significantly affected by temperature $(F=1,171 ; \mathrm{df}=4,341 ; P<0.0001)$.

Mean days from oviposition through adult emergence ranged from 19.6 to $66.2 \mathrm{~d}$ (Table 1 ) and were significantly affected by temperature $(F=2,662 ; \mathrm{df}=$ 4,$324 ; P<0.0001$ ). Pupation represented $33-40 \%$ of the total preimaginal developmental time for the temperatures studied. There were no significant differences $(F=0.95$; df $=4,158 ; P=0.44)$ in the percentage of males that emerged (47-62\%) for the five temperature regimes investigated (Table 2).

Figure 1 shows that M. gulosa exposed to $33^{\circ} \mathrm{C}$, exhibited the most rapid rate of cumulative percent- 
Table 2. Percentage of emerged male $M$. gulosa moths at five constant temperatures after exposure of individuals from egg through pupation

\begin{tabular}{ccc}
\hline \hline Temp $\left({ }^{\circ} \mathrm{C}\right)$ & No. moths emerged & $\%$ males \pm SEM \\
\hline 17 & 10 & $51.28 \pm 9.69 \mathrm{a}$ \\
21 & 23 & $48.94 \pm 9.05 \mathrm{a}$ \\
25 & 49 & $62.03 \pm 5.31 \mathrm{a}$ \\
29 & 57 & $61.29 \pm 5.55 \mathrm{a}$ \\
33 & 22 & $46.81 \pm 8.75 \mathrm{a}$ \\
\hline
\end{tabular}

Percentages followed by the same letter within a column are not significantly different $(P=0.05$; Fisher's LSD test $)$ after arcsine $[$ square $\operatorname{root}(\mathrm{x})]$ transformation of the data. Untransformed means are shown.

age mortality, reaching $60 \%$ by day 13 . Temperature regimes of 25 and $29^{\circ} \mathrm{C}$ resulted in the lowest cumulative mortality (40 and $20 \%$, respectively). Temperatures of 17 and $21^{\circ} \mathrm{C}$ resulted in nearly $70 \%$ mortality of $M$. gulos $a$ but required 27 and $49 \mathrm{~d}$, respectively, to reach that level of mortality.

Figure 2 shows that the cohorts of $M$. gulosa exposed to $17^{\circ} \mathrm{C}$ or $33^{\circ} \mathrm{C}$ exhibited $>10 \%$ mortality during the egg, first larval instars, and second larval instars. Cohorts exposed to $21^{\circ} \mathrm{C}$ experienced $>10 \%$ mortality in the egg and second larval instar. Cohorts exposed to 25 and $29^{\circ} \mathrm{C}$ experienced $<10 \%$ mortality for all stages. Only larvae held at $21^{\circ} \mathrm{C}$ experienced mortality in the spinning larval stage. Pupal mortality was $<5 \%$ for $M$. gulosa exposed to all temperatures regimes.

A linear regression model was applied to each $M$. gulosa growth stage by plotting development rate (stage duration) against temperature (Table 3) by using individuals exposed to the $17-29^{\circ} \mathrm{C}$ regimes. The lower developmental threshold for oviposition through first, second, third, fourth, and fifth instar sap-feeding larvae and pupae ranged from 12.21 to $13.68^{\circ} \mathrm{C}$ (Table 3 ). The developmental rates from oviposition to pupal eclosion for $M$. gulosa individuals held at $17,21,25$, or $29^{\circ} \mathrm{C}$ produced a highly significant $\left(r^{2}=0.96, P<0.0001\right)$ regression equation of $y=0.31 \mathrm{x}$ -3.79 with a lower developmental threshold of $12.2^{\circ} \mathrm{C}$ (Fig. 3). The degree-day accumulation for oviposition through third instar larva was 99 DD and through pupation was 322 DD by using the lower developmental threshold of $12.2^{\circ} \mathrm{C}$. Using $322 \mathrm{DD}$ as the accumulation for each generation of M. gulosa and the

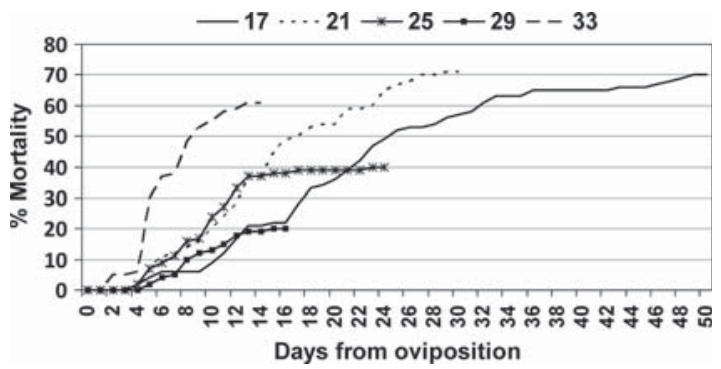

Fig. 1. Mean cumulative percentage of mortality of $M$. gulosa exposed to $17,21,25,29$, or $33^{\circ} \mathrm{C}$ temperature regimes from egg to adult. 


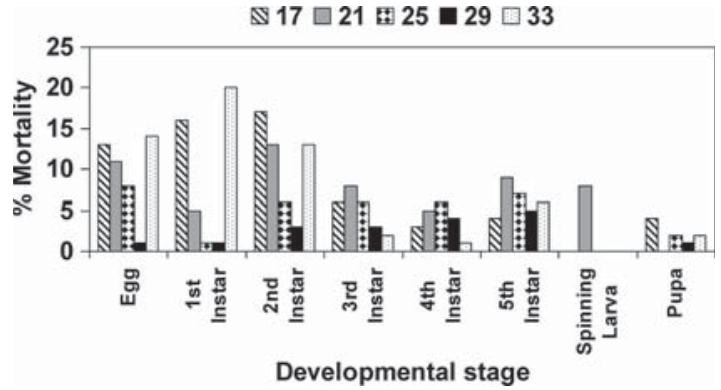

Fig. 2. Percentage of mortality by developmental stage of M. gulosa exposed to five temperatures from egg to adult.

30-yr daily average temperatures, M. gulosa can potentially complete seven generations in the San Joaquin Valley.

The maximum number of moths per trap caught in any of the walnut sites averaged $<2.5$ moths per trap per week (Fig. 4). Citrus sites attracted at most two moths per trap in the spring, very few moths during summer and at most 8.3 moths per trap in the fall (Fig. $5)$. Thus, the pheromone was demonstrated to be too weak to indicate the peaks in flights during the field season. However pheromone trapping did indicate the initial spring flight of moths in both walnuts and citrus.

Figure 6 shows that on 18 May and 29 June first instar larvae were found in green wood of walnut twigs, indicating there are two generations of $M$. gulosa attacking walnut twigs during the spring. Green twig length showed two periods of rapid growth, and larvae emerged during those periods. Later stage larvae were found on 25 May and 29 June, and evidence of emerged larvae peaked on 8 June and 6 July, also providing confirmation of two generations. Table 4 shows that there were 260 DD units between the initial male flight and first larval emergence and 490 DD units between the first and second larval emergences. The average of these intervals is $375 \mathrm{DD}$, which is greater than the 322 DD units accumulated by M. gulosa infesting zucchini under laboratory conditions.

Figure 7 shows that larvae were first found on pummelos when fruit reached an average size of $67.1 \mathrm{~cm}$ in diameter on 22 June. Peaks in numbers of first instar larvae occurred on 22 June, 6 July, 27 July, 17 August, and 14 September after which there was evidence of

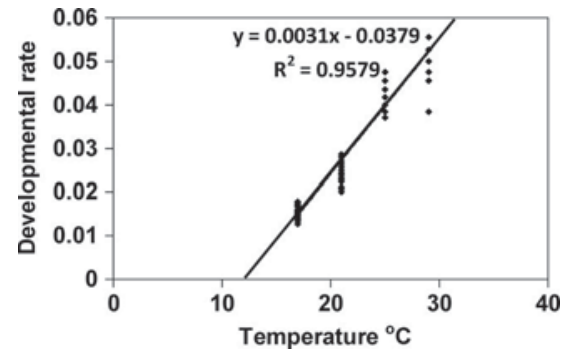

Fig. 3. Linear regression of developmental rate $(1 / \mathrm{d})$ from egg through pupation of $M$. gulosa against temperature.

larval activity, but populations declined and peaks could not be discerned. These data indicate that there were five to six generations of $M$. gulosa attacking pummelo fruit during June through October. Later stage larvae and emerged larvae somewhat confirmed generations; however, on pummelo, seasonal occurrence of these stages were not as clearly defined as on walnut twigs. DD were accumulating rapidly during the summer and significant larval development on citrus was occurring in less than the 7-d sampling interval. Table 4 shows that there were 611 DD units between the initial male flight and first larval emergence on pummelo fruit, indicating one to two generations were completed on other hosts before pummelo fruit were used as a host. Degree-day units between generations on pummelo fruit ranged from 239 to 375 and averaged $322 \mathrm{DD}$, which is the same degree-day unit accumulation observed for generations of larvae infesting zucchini in the laboratory.

Figure 8 shows that larvae were first found on oranges when fruit reached an average size of $61.8 \mathrm{~cm}$ in diameter on 17 August. Peaks in first instar larvae occurred on 17 August, 14 September, and 19 October after populations declined. These data indicate that there were three generations of $M$. gulosa attacking orange fruit during August through October. Later instar larvae and emerged larvae somewhat confirmed generations; however, densities of these stages were very low, especially during the latter part of the season. Table 4 shows that there were 1477 DD units between the initial male flight and first larval appearance on citrus, indicating five generations were completed on other hosts before orange fruit were used as a host. Degree-day units between generations on or-

Table 3. Linear regression equations, lower developmental thresholds, and degree-day accumulations for each life stage or instar of M. gulosa based upon developmental data from four constant temperature regimes

\begin{tabular}{|c|c|c|c|c|c|}
\hline Through first instar & 434 & $y=-20.56+1.58 x$ & 0.98 & 13.01 & 63.27 \\
\hline Through second instar & 407 & $\mathrm{y}=-17.71+1.29 x$ & 0.95 & 13.68 & 77.26 \\
\hline Through third instar & 366 & $y=-13.74+1.01 x$ & 0.95 & 13.59 & 98.90 \\
\hline Through spinning larva & 292 & $y=-6.59+0.53 x$ & 0.94 & 12.43 & 188.69 \\
\hline Through pupation & 278 & $\mathrm{y}=-3.79+0.31 \mathrm{x}$ & 0.96 & 12.21 & 321.84 \\
\hline
\end{tabular}




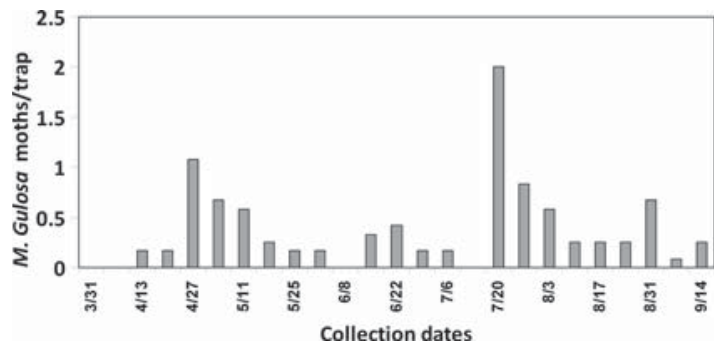

Fig. 4. Average number of M. gulosa moths per trap caught in pheromone traps in three walnut orchards during 2006 .

anges ranged from 242 to 375 and averaged 309 DD, very close to the 322 DD units between generations observed on larvae infesting zucchini in the laboratory.

\section{Discussion}

Mortality was greatest for cohorts held at 17, 21, and $33^{\circ} \mathrm{C}$, suggesting that these temperatures are not optimal for growth of M. gulosa (Fig. 1). The high rate of mortality combined with decreased growth rate at $33^{\circ} \mathrm{C}$ suggests that the upper limit of growth for $M$. gulosa lies near this temperature. Excluding this temperature, extrapolation of the linear regression equation to the $\mathrm{x}$-axis generated a lower developmental threshold of $12.2^{\circ} \mathrm{C}$. Eggs and young larval instars showed the highest mortality when exposed to the highest and lowest temperatures. The lowest levels of mortality were observed in spinning larvae and pupae, suggesting that these stages are best equipped to withstand environmental extremes. Cocoon-spinning larvae differ greatly from sap-feeding larvae, having nonfunctional feeding structures, cylindrical body structure, legs, and spinneret (Wagner et al. 2000, Guillén et al. 2001).

Temperature did not affect the percentage of male moths reaching adulthood at any specific temperature regime (Table 2). Therefore, populations that experience extremes of summer and winter temperatures in the field should not exhibit a biased sex ratio.

In the current laboratory study, surviving $M$. gulosa individuals completed at most five sap-feeding larval instars. Only one larva out of 42 completed a sixth

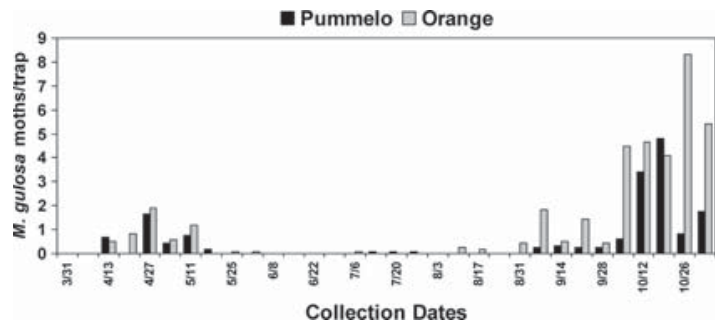

Fig. 5. Average number of M. gulosa moths per trap caught in pheromone traps in three pummelo and three orange sites during 2006

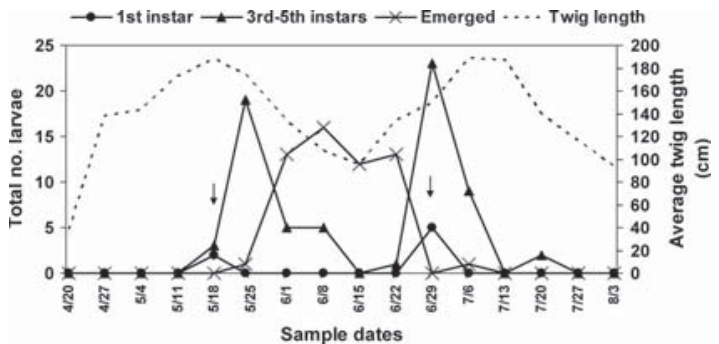

Fig. 6. Total number of first instar, third-fifth instar, and emerged larvae relative to average green wood twig length (centimeters) for three walnut orchards. Arrows indicate generational peaks in first instar larval occurrence.

sap-feeding instar in the laboratory study of Guillén and Heraty (2004). Atkins (1961) found that larvae held at a constant temperature of $26.7^{\circ} \mathrm{C}$ completed five sap-feeding instars in addition to the spinning larval instar (Atkins 1961). Wagner et al. (2000) found seven sap-feeding instars in M. arbutiella increasing in head capsule size by $\approx 0.1 \mathrm{~mm}$ per instar similar to $M$. gulosa.

Average daily temperatures below $12.2^{\circ} \mathrm{C}$ are commonly recorded in the San Joaquin Valley during November through February (Fig. 9). We would not expect development of $M$. gulosa individuals during this time and would expect high mortality of eggs and young larval instars. Periods of sustained high temperatures in the field typically occurring in July and August in the San Joaquin Valley would lead to increased mortality, especially for eggs and young instars. The eulophid parasitoids that attack M. gulosa, such as Cirrospilus coachellae Gates (Hymenoptera: Eulophidae) (Guillén et al. 2007), attack specific stages of gracillariids. Thus, high mortality of eggs and larvae due to temperature extremes may result in periods of unavailability of preferred host stages and limit successful parasitism.

Using the 322 DD interval predicted for completion of each generation, the climatic conditions in the San Joaquin Valley provide sufficient heat units for $M$. gulosa to complete approximately seven generations during a 365-d time period based on a calendar biofix of 1 January. Field studies demonstrated that there are two generations attacking walnut twigs in the spring, five to six generations attacking pummelo fruit from summer through fall, and three generations attacking orange fruit in late summer and fall. These three hosts provided overlapping resources for $M$. gulosa, allowing it to maintain populations from April through November. Walnut green wood was only available during the spring and acted as a suitable as host only when the twigs were rapidly expanding. Thus, plant growth seems to influence the timing of generations. Two periods of walnut twig growth supported two generations of M. gulosa. Citrus fruit was not suitable as a host until it approached $60 \mathrm{~mm}$ in diameter and then remained a suitable host throughout the season. This finding supports the observation that the growth phase of the host plant tissue influences oviposition. The 


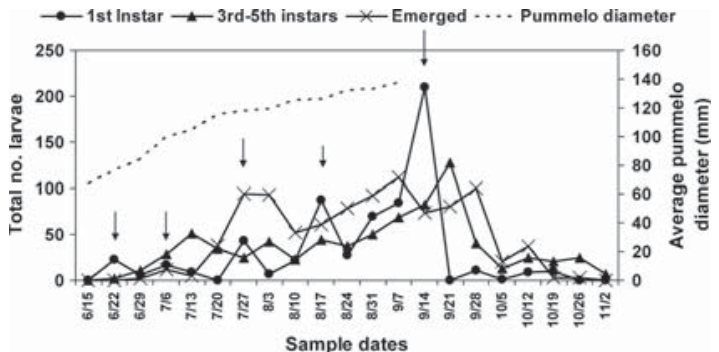

Fig. 7. Total number of first instar, third-fifth instar, and emerged larvae relative to average fruit diameter (millimeter) for three pummelo orchards. Arrows indicate generational peaks in first instar larval occurrence.

total number of generations observed on these three hosts was seven, although there were sufficient degree-day units in the early spring to support an additional generation on another host. Willows have been observed (unpublished data) to host M. gulosa throughout the year and to act as one of those early bridging host plant species.

Multiple classes of insecticides, including organophosphate, carbamate, pyrethroid, neonicotinoid, insect growth regulator, fermentation products, and sulfur, have been shown to reduce populations of $M$. gulosa in laboratory tests (Grafton-Cardwell et al. 2008). In these studies, diflubenzuron and pyriproxyfen, cyfluthrin and fenpropathrin, imidacloprid and acetamiprid, and spinosad were shown to significantly reduce the percentage of egg hatch, which is essential for preventing rind damage. The efficacy of these materials in the field is limited due to the larvae being protected by the mine and the difficulty in obtaining thorough coverage as a result of rapid fruit growth and dense canopy (Grafton-Cardwell et al. 2003, 2008; Grafton-Cardwell and Reagan 2004). Degree-day units could be used to better time treatments and so maximize the effectiveness of these insecticides. We propose that the synthetic pheromone (McElfresh et al. 2009) be used to determine the biofix of the first male flight, and by using a lower developmental threshold of $12.2^{\circ} \mathrm{C}$, calculate $322 \mathrm{DD}$ intervals for subsequent male flights and time treatments to cause mortality of eggs and early larvae to minimize mining.

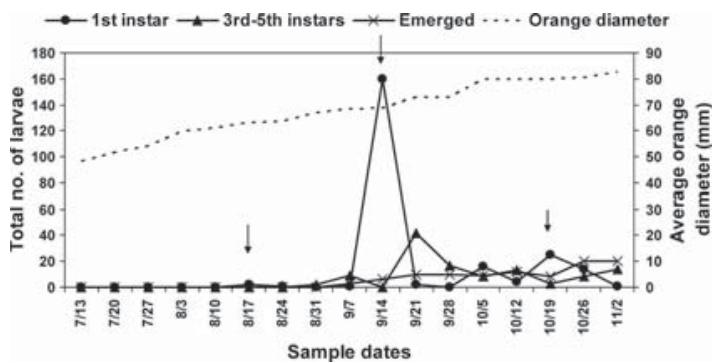

Fig. 8. Total number of first instar, third-fifth instar, and emerged larvae relative to average fruit diameter (millimeters) for three orange orchards. Arrows indicate generational peaks in first instar larval occurrence. 


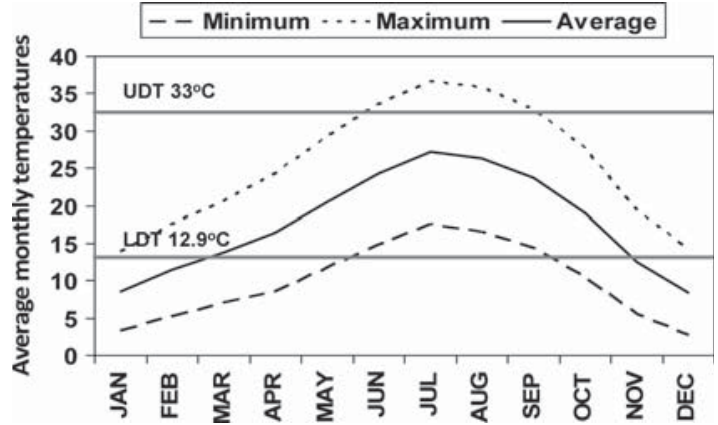

Fig. 9. Average monthly high and low temperatures (Celsius) for 1976-2006 recorded at the CIMIS weather station, Lindcove Research and Extension Center, Exeter, CA. The upper solid line indicates the suspected upper developmental threshold (UDT) of $33^{\circ} \mathrm{C}$ and the lower line the estimated LDT of $12.9^{\circ} \mathrm{C}$ for M. gulosa.

Our field studies suggest that citrus is attacked when the fruit diameter nears $60 \mathrm{~cm}, 600-650 \mathrm{DD}$ after the first male flight for pummelos and 1450-1500 DD after the first male flight for oranges. Treatments could be applied just before these events and followed up at 322 DD intervals for subsequent generations if additional treatments were warranted.

Degree-days also could be used to help time field releases of parasitoids, if the preferred host stage is known. For example, C. coachellae could be released using a 99 DD interval after male flights to target the presence of the preferred late instar M. gulosa larvae (Guillén et al. 2007). Although parasitism of late instar larvae will not prevent rind damage, it may act to reduce overall $M$. gulosa population densities. Field studies are needed to determine whether this release strategy is effective.

\section{Acknowledgments}

We thank Maria Murrietta for laboratory assistance. Partial funding for this project has been made available by the California State University Agricultural Research Institute and the Citrus Research Board.

\section{References Cited}

Amarasekare, K. G., J. H. Chong, N. D. Epsky, and C. M. Mannion. 2008. Effect of temperature on the life history of the mealybug Paracoccus marginatus (Hemiptera: Pseudococcidae). J. Econ. Entomol. 101: 1798-1804.

Atkins, E. L., Jr. 1961. Citrus peel miner. Calif. Citrograph. 46: 369-370.

Atkins, E. L., Jr. 1971. The citrus peel miner, more problems in the desert. Calif. Citrograph 56: 245-246, 267.

Finch, S. M. 2003. Ecological studies of and the foreign exploration for citrus peelminer, Marmara gulosa Guillen and Davis. M.S. thesis, California Polytechnic State University, San Luis Obispo.
Gibson, R., D. Bacon, D. Langston, D. Kearns, and R. Gibson. 1997. The citrus peel miner, Marmara salictella, in Arizona grapefruit in 1994. 1997 Citrus Research Report, University of Arizona, College of Agriculture Series 109: $1-6$.

Gilmore E. C., Jr., and J. S. Rogers. 1958. Heat units as a method of measuring maturity in corn. Agron. J. 50: 611615 .

Godfrey, K., D. A. Mayhew, K. Daane, and D. Haines. 2003. Seasonal dynamics of the citrus peelminer in Tulare County, pp. 29-32. In D. M. Woods (ed.), California Department of Food and Agriculture, Biological Control Program Annual Summary, 2002. California Department of Food and Agricultural Plant Health and Prevention Services, Sacramento, CA.

Grafton-Cardwell, E. E., and C. A. Reagan. 2004. Citrus peelminer insecticide efficacy trials, 2003. Arthropod Manag. Tests 29: D10.

Grafton-Cardwell, B., C. Reagan, and J. Stewart. 2003. Citrus peelminer evades chemical control. Univ. Calif. Plant Prot. Q. 13: 1-7.

Grafton-Cardwell, E. E., G. M. Montez, C. A. Reagan, R. Dunn, and Y. Ouyang. 2008. Response of citrus peelminer Marmara gulosa Guillén and Davis (Lepidoptera: Gracillariidae) stages to various insecticides. Pest Manag. Sci. 64: 1143-1150.

Guillén, M., and J. M. Heraty. 2004. Instar differences in Marmara gulosa Guillén and Davis (Lepidoptera: Gracillariidae). Ann. Entomol. Soc. Am. 97: 1227-1232.

Guillén, M., D. R. Davis, and J. M. Heraty. 2001. Systematics and biology of a new, polyphagous species of Marmara (Lepidoptera: Gracillariidae) infesting grapefruit in the southwestern United States. Proc. Entomol. Soc. Wash. 103: $636-654$

Guillén, M., J. M. Heraty, and R. F. Luck. 2003. Seasonal variation and infestation incidence by Marmara gulosa (Lepidoptera: Gracillariidae) on grapefruit in the Coachella valley, California. J. Econ. Entomol. 96: 577583.

Guillén, M., R. F. Luck, and J. M. Heraty. 2007. Preferred host stages, clutch size, and sex allocation by Cirrospilus coachellae (Hymenoptera: Eulophidae), a parasitoid of the citrus peelminer Marmara gulosa (Lepidoptera: Gracillariidae) with a view to its rearing and release as a biological control agent. Biol. Control 40: 264-272.

McElfresh, J. S., J. A. Moreira, E. E. Grafton-Cardwell, D. H. Headrick, J. M. Heraty, M. Guillén, and J. G. Millar. 2009. Novel lepidopteran sex pheromone components from Marmara gulosa (Lepidoptera: Gracillariidae). J. Econ. Entomol. 102: 574-584.

Reeves, E. L. 1995. Citrus peel miner problems. Calif. Plant Pest Dis. Rep. 14-16.

Wagner, C. L., J. L. Loose, T. D. Fitzgerald, J. A. De Benedictis, and D. R. Davis. 2000. A hidden past: the hypermetamorphic development of Marmara arbutiella (Lepidoptera: Gracillariidae). Ann. Entomol. Soc. Am. 93: 59-64.

Winston, P. W., and D. H. Bates. 1960. Saturated solutions for the control of humidity in biological research. Ecology 41: 232-237.

Received 6 December 2010; accepted 5 April 2011. 